\title{
ADOLESCENT AMENORRHEA
}

\author{
S. J. Behrman \\ Professor of Obstetrics and Gynecology and Director of \\ The Center for Research in Reproductive Biology \\ University of Michigan Medical School, Ann Arbor, Mich.
}

From the foregoing papers it is abundantly clear that the adolescent provides a veritable Pandora's Box of clinical problems, including various degrees of failure of fusion of the muillerian ducts; upsets of the delicate balance of a hormonal relationship and the far reaching effects of these inter-relationships; the problems of chromosomal aberrancies; prediliction of the ovary to tumor formation; the disturbing effects of systemic disease, and the disrupting influences of the psyche and environment, of which amenorrhea is but one symptom.

When one realizes how much can go wrong the wonder of it all is how so many survive at all. Because of the tremendous psychologic impact of the onset of menstruation, it is now well recognized that the modern mother tends to prepare her daughter for the event. All too often, if the menarche does not appear at the time that the mother's experience leads her to believe it should, the mother will become concerned and bring the problem to the attention of the physician. In most instances, the astute gynecologist will easily see the sources of concern and can placate both the mother and patient. However, it is essential to realize that the late onset of menses, e.g. 16 years and over, may well be indicative of some endocrine dysfunction or delayed development of the reproductive system, and one purpose of this investigation is to discover to what extent it will later influence the fertility potential.

Environment, physical condition and socioeconomic status also affect the age of menarche. Sexual stimulation may bring about the earlier menarche, as seen in some primitive tribes where social customs do not frown upon promiscuity. Anemia and other chronic disease, as well as malnutrition and psychic stress, all have an inhibiting effect and tend to produce a later menarche. Delayed menarche is a term applied when menses have not started by the age of 16 . When menses have not appeared by the age of $\mathbf{1 7}$ this should be considered as primary amenorrhea. Delay may be due to physiologic, anatomic, pathological, or constitutional causes. It should also be realized that poor general health and inadequate nutrition, hypothyroidism, detrimental environmental conditions, obesity and psychic disturbances can all cause a delay in the menarche. Thus, investigation should not be delayed beyond the age of 16 .

The problem of adolescent amenorrhea is, therefore, significant not only because of its incidence, but because it has many etiologic origins, several of which, at the moment, defy correction, and most of which will have profound impact on the young female's everyday life and later reproductive potentialities. Furthermore, there is no unanimity of opinion among the clinicians as to the definition of primary amenorrhea, what constitutes adequate investigation, and what therapeutic measures should or should not be instituted.

For these reasons, a prospective and ongoing program was instituted in 1960 to study the problem of both primary and secondary amenorrhea. This material ${ }^{1}$ has now been under study for some six years and this presentation must only be considered as an interim report. It is important to note that the cases here are unselected and that this very fact has considerable significance when 
evaluating relative frequencies of any particular condition. At the time the study began, we defined primary amenorrhea as any patient who had never menstruated and secondary amenorrhea as one who had missed at least four periods. The total number of cases presented here number 370 , of which 304 are secondary and 66 are primary, and they are further divided into age groups 13 to 20 and 21 to 35 years of age.

Beside the personal and family history, a physical and pelvic examination plus endoscopic evaluation was done. Wherever possible, $\mathrm{X}$-ray of the skull, maturation indices, nuclear sex chromatin, protein bound iodine (PBI), follicular stimulating hormone (FSH), estrogens, and 17-ketosteroids were done, and either culdoscopy, celioscopy, gynecography or laparotomy was performed wherever possible. In 60 of the 66 cases of primary amenorrhea the ovary was visualized. Selected cases had karyotypes done and other appropriate special studies.

\section{Results}

The cases of secondary amenorrhea show an age distribution very much in parallel with MacArthur's report, ${ }^{2}$ with a mean age of onset of the menarche at 13.2 years with limits of 8 to 21 ; almost all had started menses by the age of 17 . (TABLE 1).

TABLE 2 summarizes the cases of primary amenorrhea. The first observation is that 17 of 66 , or 25 percent of etiologic factors in primary amenorrhea are chromosomal in origin. If one were then to remove the cases of primary amenorrhea that are readily treated due to some systematic disease, e.g. thyroid, adrenal, systemic disease, pregnancy or delayed menses, the incidence of chromosomal defects rises to 46 percent, which parallels the original suggestion of Jacobs ${ }^{3}$ and Phillip, ${ }^{4}$ who first indicated the high incidence of chromosomal defects in primary amenorrhea.

Nine of 66 cases were due to developmental defects, e.g. vaginal agenesis. It is interesting to observe that three of the cases were not recognized until after the age of 20 , indicating failure of pelvic examination at the time of clinical evaluation and that the most propitious time for reconstruction of the vagina had already passed. It is of interest to note too that two cases with absence of the vagina had uteri with functioning ovaries and the presence of endometriosis.

It will be noted that of the seven cases listed as Turner's Syndrome, only five showed the XO complement and two were XO/XY mosaics, yet all had the streak ovary. In the ovarian deficiency states, it is interesting to note that varying developmental stages of the ovary were seen from the streak through the somewhat larger ovary, but which was afollicular compared with the normal-sized ovary which was multi-follicular and even with four cases which were called polycystic ovary and more closely resembled the ovary of Stein and Leventhal. Of more significance is the fact that only 20 percent of these cases of primary amenorrhea to date could be made to menstruate, and 29 of the 66 will never menstruate either because of chromosomal or developmental errors. The significance of this for future reproduction is most important. A glance at TABLE 2 where the secondary amenorrheas are reviewed is also illuminating. There are 42 cases of pituitary failure, of which only five recovered following therapy. There are also 17 cases of secondary ovarian failure. This latter group is extremely interesting and has been the subject of considerable discussion by Keetel and Bradbury. 5 They have termed this condition "premature ovarian failure." Although some of these cases had actually had children before cessation of their menses, others had never had normal periods, with the exception of more or less regular menstrual flows for three to four years prior to developing permanent 
TABLE 1

SBCONDARY AMENORRHEA

MARCH, 1966

\begin{tabular}{lcc}
\hline \multicolumn{1}{c}{ Etiolosy } & Age 13-20 years & Ases 20-35 years \\
\hline Probably hypothalamic & $23(11)$ & $17(1)$ \\
Psychoses \& P. disorders & $8(3)$ & $8(2)$ \\
Obesity & 1 & $12(3)$ \\
\hline Pituitary tumor & 15 & $6(2)$ \\
Pituitary failure & $27(2)$ & $27(5)$ \\
\hline Ovarian tumor & $11(5)$ & $37(27)$ \\
Polycystic disease & 5 & 12 \\
Ovarian failure & $4(2)$ & $7(4)$ \\
\hline Thyroid disturbance & $3(2)$ & $20(10)$ \\
Adrenal disturbance & - & $11(4)$ \\
\hline Endometrial & $12(4)$ & $7(1)$ \\
\hline Systemic disease & $24(4)$ & $32(5)$ \\
\hline Unclassified & $108^{* *}$ & $196 *$ \\
\hline
\end{tabular}

- 120 cases treated with 64 or $50 \%$ recovery.

** 33 or $35.6 \%$ recovery.

TABLE 2

Primary Amenorrhea

MARCH, 1966

\begin{tabular}{lcc}
\hline \multicolumn{1}{c}{ Etiology } & Age 13-20 years & Age 20-35 yeare \\
\hline Personality disorder & 3 & 1 \\
Pituitary tumor & 1 & 5 \\
Pituitary selective deficiency & 1 & 7 \\
\hline Ovarian deficiency (streak) & 3 & 3 \\
Polycystic disease & 1 & 6 \\
Turner's syndrome & 1 & $1(1)$ \\
\hline Thyroid (hypo) & $1(1)$ & $1(1)$ \\
Adrenal (hyper) & $2(1)$ & - \\
\hline Stenotic cx. ut. hypoplasia & 1 & 3 \\
Vaginal agenesis & 2 & 3 \\
Uterine absence & 3 & 1 (1) \\
\hline Pseudohermaphrodite & - & 1 \\
\hline Pregnant & $1(1)$ & 4 \\
Delayed menses & $2(2)$ & $36^{*}$ \\
Systemic disease & $1(1)$ & \\
Unclassified & $30^{*}$ & \\
\hline
\end{tabular}

- $20 \%$ recovery. 
ovarian failure. I feel sure some of these latter cases must constitute a degree of ovarian hypoplasia capable of some menstruation and which have then prematurely failed leading to a hypergonadotropic state. As I have observed before, ${ }^{1}$ it is interesting to observe that the incidence of thyroid disturbance as a cause of either primary or secondary amenorrhea does not exceed 3.5 percent and consequently caution the injudicious use of thyroid as a panacea for amenorrhea. Of the 120 cases treated in this group, only 64 or 50 percent recovered.

Now, it is obvious that primary or even secondary adolescent amenorrhea is a serious prognosticator for the future fertility of a young female. If one were to study some of the demographic reports ${ }^{6}$ on the relationship of onset of the menarche and later fertility, one is impressed by the relative decrease in fertility and increase in sterility as the age of onset of menarche goes up. Makuda ${ }^{7}$ reports on 370 Japanese females who were studied, where the sterility index of those females who started menstruating at the age of 12 was approximately 2 ; in those who started at the age of 14 the index was 6 , and in those who started at the age of 18 the index was 20 . Clearly then, primary amenorrhea, secondary amenorrhea, and even delayed menses are all indicators of future reproductive problems and in that order of severity.

Certainly chromosomal defects and ovarian deficiency states seem to play the major role in adolescent amenorrhea, conditions with which the clinician and practitioner who sees these young females must become familiar. For this reason, a method for classifying these problems is presented based on the original classification of Kinch and his co-workers, ${ }^{8}$ which seems to offer a reasonably logical approach (TABLE 3). In this classification, it is important for the clinician to examine the patient thoroughly with special reference to the body formation, the nuclear chromatin pattern, and where feasible a karyotype supplemented by gonadotrophin, estrogen and 17-ketosteroid estimation, and ideally supported

TABLB 3

\begin{tabular}{|c|c|c|c|c|c|}
\hline & $\begin{array}{c}\text { I } \\
\begin{array}{c}\text { Pure gonadal } \\
\text { agenesis }\end{array}\end{array}$ & $\begin{array}{c}\text { II (a) } \\
\text { Partial } \\
\text { gonadal } \\
\text { dysgenesia }\end{array}$ & $\begin{array}{c}\text { II (b) } \\
\text { Partial } \\
\text { gonadal } \\
\text { dysgenesis }\end{array}$ & $\begin{array}{c}\text { III } \\
\text { Ovarian } \\
\text { agenesis }\end{array}$ & $\underset{\text { IV }}{\underset{\text { Ovarian }}{\text { hyperplasia }}}$ \\
\hline $\begin{array}{l}\text { Body formation } \\
\text { ( } x \text {-rays bones) }\end{array}$ & $\begin{array}{l}\text { Extragenital } \\
\text { anomalies }\end{array}$ & Turner & $\begin{array}{l}\text { Turner with } \\
\text { other patterns }\end{array}$ & $\begin{array}{l}\text { Eunochoid } \\
\text { features }\end{array}$ & 9 \\
\hline $\begin{array}{l}\text { Nuclear chromatin } \\
\text { pattern }\end{array}$ & $X Y(46)$ & $\mathrm{XO}(45)$ & $\begin{array}{l}\text { Variable } \\
\mathrm{XO} / \mathrm{XY} \text { mosaic }\end{array}$ & $X \times(46)$ & $X X(46)$ \\
\hline Gonadotrophin & A & A & A & A & Variable \\
\hline Estrogen & 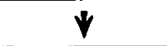 & $\boldsymbol{v}$ & $v$ & $\forall$ & Variable \\
\hline $\begin{array}{l}\text { Culdoscopy } \\
\text { Pnueumohysterogram } \\
\text { Laparotomy }\end{array}$ & $\begin{array}{l}\text { Streak } \\
\text { ovary }\end{array}$ & Streak & $\begin{array}{l}\text { Streak or } \\
\text { larger }\end{array}$ & $\begin{array}{l}\text { Afollicular } \\
\text { follicular }\end{array}$ & $\begin{array}{l}\text { Small with } \\
\text { normal } \\
\text { Complement }\end{array}$ \\
\hline
\end{tabular}

V. Polycyatic ovary

VI. $2^{\circ}$ Ovarian failure

(a) Hypothalamo-pituitary axis

(b) Thyroid

(c) Adrenal 
by culdoscopy, pneumohysterogram, or laparotomy where possible. In order to describe the size and development of the ovary, these are then classified into six major groups: Group I would be pure gonadal agenesis with a male XY (46) type chromosome and hypergonadotrophic state and streak ovary; Group II (a) would be the partial gonadal dysgenesis of Turner with the typical Turner body formation and XO (45) karyotype and streak ovary; Group II (b) would include the body configuration of Turner, but the $\mathrm{XO} / \mathrm{XY}$ mosaic as a variable; Group III would be the XX (46) type female of the tall stature who would be hypergonadotrophic with ovarian agenesis. In these instances the ovary might be of the streak type or occasionally somewhat larger, with or without follicular cysts. ${ }^{\theta}$ On occasion these follicular cysts are present even in the absence of a hypergonadotrophic state and it makes for interesting speculation as to their origin. Govan and Mukherjee, ${ }^{10}$ Stange, ${ }^{11}$ and others have reported this type of ovary with follicular cysts in newborn infants born of mothers with severe preeclamptic toxemia and raise the question as to whether this might not be due to excessive maternal pituitary stimulation of the fetal ovary. Group IV is the girl with typical female body formation, XX (46) nuclear pattern, with a small ovary but of normal complement. Group V would be the polycystic ovary, and Group VI would be secondary ovarian failure due to other causes, e.g. adrenal hyperplasia or hypothyroidism. On the extreme left hand side of this table would be the ovotestis or testicular feminizing ovary with masculinization.

\section{Conclusion}

In conclusion, it now remains for me only to state the obvious:

(1) As by far the greatest number of contemporary young females have started their menses by the age of 16 or 17 , a delay beyond this age should be considered as primary (or adolescent) amenorrhea and, therefore, a full evaluation at this time prior to institution of therapy is in order. This applies equally well to secondary (adolescent) amenorrhea of longer than six months duration. Mention is made of evaluation prior to therapy as a warning to those who so liberally give estrogen containing hormones, and to them I would advise rather considerable restraint to avoid vigorous over-treatment with endocrine therapy, especially estrogen, which will accelerate epiphyseal closure and is clearly unwarranted. The pubescent organism is best given every opportunity to evolve spontaneously through the activation of normal developmental mechanisms.

(2) Inasmuch as elaborate and costly studies may be required to elucidate the cause of amenorrhea, it is important to extract all information from history, physical and pelvic examination, eating and recreation habits, emotional adjustment, and environment.

(3) Early diagnosis is important to permit correction of reversible etiologic factors, to permit vaginal reconstruction at a propitious time, and permit those unfortunate females who will be permanently sterile the privilege of adjusting their lives accordingly.

(4) Evidence suggests that primary or secondary adolescent amenorrhea is associated with a definite decrease in fertility potential.

(5) Because almost one-third of adolescent primary amenorrheas are due to chromosomal defects, nuclear sex chromatin and karyotypes, culdoscopy, and laparotomy with gonadal biopsy where possible is essential.

(6) Finally, a useful working classification is presented as a guide in approach to such ovarian deficiencies. 


\section{References}

1. Behrman, S. J. 1964. Management of secondary amenorrhea. In Advances in the Treatment of Menstrual Dysfunction. A. F. Goldfarb, Ed.: 3. Lea \& Febiger, Philadelphia, $\mathbf{P a}$.

2. McArthur, J. W. 1957. Adolescent menstrual disorders. Progr. Gynec. 3: 153-166.

3. Jacoss, P. A. et al. 1961. Cytogenic studies in primary amenorrhea. Lancet $1: 1183-$ 1188.

4. Phulip, J. 1965. Primary amenorrhea: A study of 101 cases. Fertil. Steril. 16(6), 795.

5. KeEtel, W. C. \& J. T. Bradbury. 1964. Premature ovarian failure, permanent and temporary. Amer. J. Obstet. Gynec. 89(1), 83-96.

6. SouthaM, A. L. \& R. M. Richart. 1966. The prognosis for adolescents with menstrual abnormalities. Amer. J. Obstet. Gynec. 94(5): 637.

7. Makuda, T. \& K. Hort. 1939. Menarche and sterility. Jap. J. Obstet. Gynec. 22 i 199.

8. Kinch, R. A., E. R. Piunketr, M. S. Smout \& D. H. Carr. 1965. Primary ovarian failure. Amer. J. Obstet. Gynec. 91(5): 630-644.

9. Knut, B. 1965. Primary amenorrhea. Acta Obstet. Gynec. Scand. XLIV: Suppl. 4.

10. Govan, A. D. T. \& C. L. Mukherjee. 1950. Maternal toxemia and fetal ovarian activity. J. Obstet. Gynaec. Brit. Comm. 57, 525.

11. StANGE, H. H. 1959. Therapeutic problems associated with connatal ovarian malformations. Medical News (Schering) 4; 132. 